\title{
Photodynamic Therapy of Necrobiosis Lipoidica - A Multicenter Study of 18 Patients
}

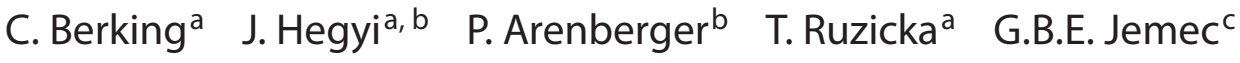

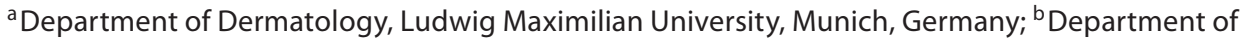 \\ Dermatovenereology, Faculty Hospital Královské Vinohrady, Charles University, Prague, Czech Republic; \\ 'Department of Dermatology, Health Sciences Faculty, University of Copenhagen, Roskilde Hospital, \\ Roskilde, Denmark
}

\section{Key Words}

Methyl aminolevulinate $\cdot$ Necrobiosis lipoidica .

Photodynamic therapy, topical treatment

\begin{abstract}
Background: Necrobiosis lipoidica (NL) is a granulomatous skin disease of unknown origin, and no reliably effective treatment option exists to handle this often disfiguring disease. Recently, a patient with long-lasting NL was reported to be cured by topical photodynamic therapy (PDT). Objective: To evaluate the overall potential of PDT in the treatment of NL on the lower legs. Methods: Retrospective study of 18 patients (aged 16-62 years) from 3 European university departments of dermatology treated with PDT for NL. Methyl aminolevulinate or 5-aminolevulinic acid were used as topically applied photosensitizers. Illumination followed with red light-emitting diode light. Results: Complete response was seen in 1/18 patients after 9 PDT cycles, and partial response in 6/18 patients (2-14 PDT cycles) giving an overall response rate of $39 \%$ (7/18). Conclusion: Although almost $40 \%$ of the cases showed some degree of response, PDT cannot currently be recommended as first-line therapy of NL. Subpopulations of therapy-resistant NL patients may, however, benefit from PDT.

Copyright $\odot 2008$ S. Karger AG, Basel
\end{abstract}

\section{Introduction}

Necrobiosis lipoidica (NL) is a rare granulomatous skin disease of unknown origin, first described by Oppenheimer in 1929 in association with diabetes mellitus. In 1935, Goldsmith reported the first case in a nondiabetic patient [1]. Clinically, NL appears as irregular or circular lesions ranging in color from red brown, dark purple to yellow. Ulcerations and telangiectasia may occur [2]. Most commonly the anterior portions of the lower legs are involved, but other localizations have been described [3].

Since the lesions of NL are not only aesthetically troublesome, but may also be accompanied by pain or secondarily infected ulcerations, treatment of this disease is necessary. Several therapeutic approaches have been described for NL, including topical, intralesional and systemic application of corticosteroids, topical retinoids, PUVA, cyclosporine and chloroquine [4-9]. However, these treatment modalities are of limited success, and new approaches are wanted to handle this often frustrating and cosmetically disturbing disease.

In 2006, Heidenheim and Jemec [10] successfully treated a diabetic patient with a 10 -year history of NL by topical photodynamic therapy (PDT). They observed a

\section{KARGER}

Fax +41613061234 E-Mail karger@karger.ch www.karger.com
Carola Berking, MD

Department of Dermatology, Ludwig Maximilian University of Munich

Frauenlobstrasse 9-11, DE-80337 Munich (Germany)

Tel. +49 895160 6010, Fax +498951606322

E-Mail Carola.Berking@med.uni-muenchen.de 
Table 1. Overview of 18 patients with NL treated with PDT

\begin{tabular}{|c|c|c|c|c|c|c|c|c|c|c|c|c|c|}
\hline $\begin{array}{l}\mathrm{Pa}- \\
\text { tient }\end{array}$ & Sex & $\begin{array}{l}\text { Age } \\
\text { years }\end{array}$ & $\begin{array}{l}\text { Insti- } \\
\text { tution }\end{array}$ & $\begin{array}{l}\text { Duration } \\
\text { of disease } \\
\text { years }\end{array}$ & $\begin{array}{l}\text { Diabetes } \\
\text { comor- } \\
\text { bidity }\end{array}$ & Biopsy & $\begin{array}{l}\text { Treatment modalities } \\
\text { prior to PDT }\end{array}$ & $\begin{array}{l}\text { PDT } \\
\text { cycles }\end{array}$ & $\begin{array}{l}\text { Type of PDT/ } \\
\text { energy } \\
\mathrm{J} / \mathrm{cm}^{2}\end{array}$ & $\begin{array}{l}\text { Pain } \\
\text { score }\end{array}$ & Cooling & $\begin{array}{l}\text { Interval be- } \\
\text { tween treat- } \\
\text { ment and } \\
\text { evaluation }\end{array}$ & $\begin{array}{l}\text { Out- } \\
\text { come of } \\
\text { therapy }\end{array}$ \\
\hline 1 & $\mathrm{~F}$ & 46 & $\mathrm{DK}$ & 6 & no & yes & allopurinol & 9 & MAL/37 & 4 & yes & 3 months & CR \\
\hline 2 & $\mathrm{~F}$ & 17 & $\mathrm{CZ}$ & 2 & no & n.a. & TS, OTS, ILS & 3 & MAL/37 & 7 & yes & 4 weeks & PR \\
\hline 3 & $\mathrm{M}$ & 32 & $\mathrm{D}$ & 8 & no & yes & TS & 6 & MAL/37 & 6 & yes & 6 weeks & $\mathrm{PR}$ \\
\hline 4 & $\mathrm{~F}$ & 62 & $\mathrm{D}$ & 26 & no & yes & TS, cryo. & 6 & MAL/37 & 5 & yes & 6 weeks & PR \\
\hline 5 & $\mathrm{M}$ & 31 & $\mathrm{DK}$ & 1 & no & no & TS & 5 & $\mathrm{MAL} / 37$ & 4 & no & 8 weeks & $\mathrm{PR}$ \\
\hline 6 & $\mathrm{~F}$ & 25 & $\mathrm{DK}$ & 2 & yes & no & OTS & 14 & MAL/37 & 5 & no & 4 months & PR \\
\hline 7 & $\mathrm{M}$ & 57 & $\mathrm{DK}$ & n.a. & $\mathrm{DM} 2$ & n.a. & TS, tacrolimus & 2 & $\mathrm{MAL} / 37$ & n.a. & no & 1 year & $\mathrm{PR}$ \\
\hline 8 & $\mathrm{~F}$ & 57 & $\mathrm{D}$ & 4 & no & yes & TS & 8 & MAL/37 & 2 & yes & 1 week & NR \\
\hline 9 & $\mathrm{~F}$ & 60 & $\mathrm{D}$ & 19 & no & yes & TS, PUVA & 6 & $\mathrm{MAL} / 37$ & 7 & yes & 3 weeks & NR \\
\hline 10 & $\mathrm{~F}$ & 35 & $\mathrm{D}$ & $4-5$ & no & yes & TS, SS & 6 & MAL/37 & 2 & yes & 4 weeks & NR \\
\hline 11 & $\mathrm{~F}$ & 38 & $\mathrm{CZ}$ & 4 & no & yes & TS, OTS, ILS & 3 & ALA/75 & 4 & no & 4 weeks & NR \\
\hline 12 & $\mathrm{~F}$ & 27 & $\mathrm{CZ}$ & 5 & DM1 & yes & $\begin{array}{l}\text { TS, OTS, ILS, } \\
\text { PUVA, imiquimod }\end{array}$ & 5 & ALA/40-75 & 4 & no & 6 weeks & NR \\
\hline 13 & $\mathrm{~F}$ & 19 & $\mathrm{D}$ & 3 & DM2 & yes & $\begin{array}{l}\text { PUVA }(28 \times) \\
\text { tacrolimus }\end{array}$ & 6 & MAL/37 & 4 & yes & 8 weeks & NR \\
\hline 14 & $\mathrm{~F}$ & 43 & $\mathrm{D}$ & 4 & no & yes & TS & 8 & MAL/37 & 3 & yes & 8 weeks & NR \\
\hline 15 & $\mathrm{~F}$ & 52 & $\mathrm{CZ}$ & $2-3$ & no & no & TS, OTS, ILS & 4 & ALA/75 & 5 & no & 8 weeks & NR \\
\hline 16 & M & 16 & DK & 8 & DM1 & no & pentoxifylline & 2 & MAL/37 & 10 & yes & 8 weeks & $\mathrm{NR}^{\mathrm{a}}$ \\
\hline 17 & $\mathrm{~F}$ & 17 & $\mathrm{DK}$ & 3 & no & yes & TS & 6 & $\mathrm{MAL} / 37$ & 4 & no & 8 weeks & NR \\
\hline 18 & $\mathrm{~F}$ & 42 & DK & 2 & no & yes & none & 6 & MAL/37 & n.a. & yes & 1 year & NR \\
\hline
\end{tabular}

D = Germany; DK = Denmark; CZ = Czech Republic; DM1/DM2 = diabetes mellitus type 1/2; n.a. = not assessed; TS = topical corticosteroids; OTS = occlusive topical corticosteroids; ILS = intralesional corticosteroids; cryo. = cryotherapy; PUVA = psoralen and ultraviolet $\mathrm{A} ; \mathrm{SS}=$ systemic corticosteroids; $\mathrm{ALA}=5$-aminolevulinic acid; $\mathrm{CR}=$ complete response; $\mathrm{PR}=$ partial response; $\mathrm{NR}=$ no response.

a Stopped due to pain.

complete remission of the NL lesion after 6 cycles of PDT using methyl aminolevulinate (MAL, $160 \mathrm{mg} / \mathrm{g}$ ) and red light. This single case report published so far motivated us to perform a study in a series of patients in order to evaluate the overall efficacy of this therapeutic modality to control this often therapy-resistant and uncontrolled disease.

\section{Patients and Methods}

This study was conducted in 3 European university departments of dermatology: Roskilde Hospital (Roskilde, Denmark), Ludwig Maximilian University (Munich, Germany) and the Faculty Hospital Královské Vinohrady (Prague, Czech Republic). Eighteen patients ( 14 female, 4 male) with NL of the lower legs and resistant to conventional therapies were included ( $\mathrm{ta}$ ble 1). The average age of the patients was 38 years with a range of 16-62 years. Comorbidity of diabetes mellitus was present in $28 \%$ of the patients $(5 / 18)$. The duration of NL was $1-8$ years in 16 patients and 19 and 26 years in 2, respectively. In 4 patients, lesions were partially ulcerated. A diagnostic biopsy was performed in 12 patients, while in 6 there was no histological confirmation of the disease, but the clinical appearance was clearly NL. Each patient gave informed consent for the planned procedure.

PDT was initiated by the topical application of a photosensitizer onto the lesions. We used MAL $(160 \mathrm{mg} / \mathrm{g})$ in 15 patients and 5 -aminolevulinic acid ( $200 \mathrm{mg} / \mathrm{g})$ in 3 . The lesions were then covered with occlusive and light-protective dressing for $3 \mathrm{~h}$. After removal of the dressing the MAL-treated areas $(n=15)$ were illuminated with red light at a dose of $37 \mathrm{~J} / \mathrm{cm}^{2}$ (Aktilite lamp, Photocure ASA, Norway) and the 5-aminolevulinic-acid-treated areas $(\mathrm{n}=2)$ at a dose of $75 \mathrm{~J} / \mathrm{cm}^{2}$. The third 5-aminolevulinic-acidtreated patient received $75 \mathrm{~J} / \mathrm{cm}^{2}$ for the first 2 cycles and $40 \mathrm{~J} / \mathrm{cm}^{2}$ further on. During illumination, the respective areas were cooled in 11 patients to relieve burning sensations. Three patients received analgesics (NSAIDs), 1 patient received local anesthesia with bupivacaine and 1 with mepivacaine. With respect to pain during illumination, patients tended to react differently during each session. On a $10-\mathrm{cm}$ visual analog scale from 0 (no pain) to 10 (unbearable pain), the level ranged from 2 to 10 with a median of 5 . 
Intervals between separate PDT cycles ranged from 1 to 3 weeks. In 4 patients the intervals exceeded 1 month. The number of PDT cycles performed ranged from 2 to 14 per patient with an average of 6 . These variations in the treatment protocol were either due to a complete lack of effect, unacceptable side effects or the refusal of the patient to continue the treatment.

\section{Results}

The interval between PDT and evaluation of therapy outcome was 1 week to 4 months in 16 patients and 1 year in 2. One patient showed complete response after 9 cycles, 6 patients showed partial response after 2-14 cycles and 11 patients showed no response (table 1, fig. 1). Adverse events included erythema of the treated areas in 9 patients, crusting in 6 patients, pustules, exudation and blistering, respectively, in 1 patient. The only patient with complete response to therapy was a 46 -year-old female without diabetes comorbidity and with a 6-year history of NL located on the shins of both legs. Allopurinol (200 $\mathrm{mg}$ daily for 3 months) had been given prior to MAL-PDT without effect. This patient's lesions had shown ulcerations and a slight hyperpigmentation at the edges. Complete response was observed after 9 cycles of PDT over a period of 8 months. The patient reported no adverse events during the treatment period, and the average pain score during illumination was $4 / 10$.

The 6 patients with partial response were all treated with MAL-PDT: 3 females and 3 males with an age of 17-62 years. The duration of NL was 1-3 years in 4 patients, and 8 and 26 years in 1 patient, respectively. Diabetes comorbidity was present in 2 of the 6 patients. Lesions were ulcerated in 2 patients and hyperpigmented in 1. All of them had been treated with topical corticosteroids prior to PDT. One patient each had previously received intralesional corticosteroids, tacrolimus, PUVA and cryotherapy. Five of the 6 patients received 2-6 cycles of PDT, while 1 received 14 cycles. The pain score during PDT ranged from $4 / 10$ to $10 / 10$. After therapy, 3 patients had transient erythema, 1 had a bullous reaction and 1 pustules. The partial response to PDT was observed after a period of 1 month to 1 year after therapy.

\section{Discussion}

NL is a cosmetically disturbing disease which may cause pain or itching. Therapeutic efforts to treat NL have been frustrating in the past. Topical and intralesional corticosteroids seem to be the most promising
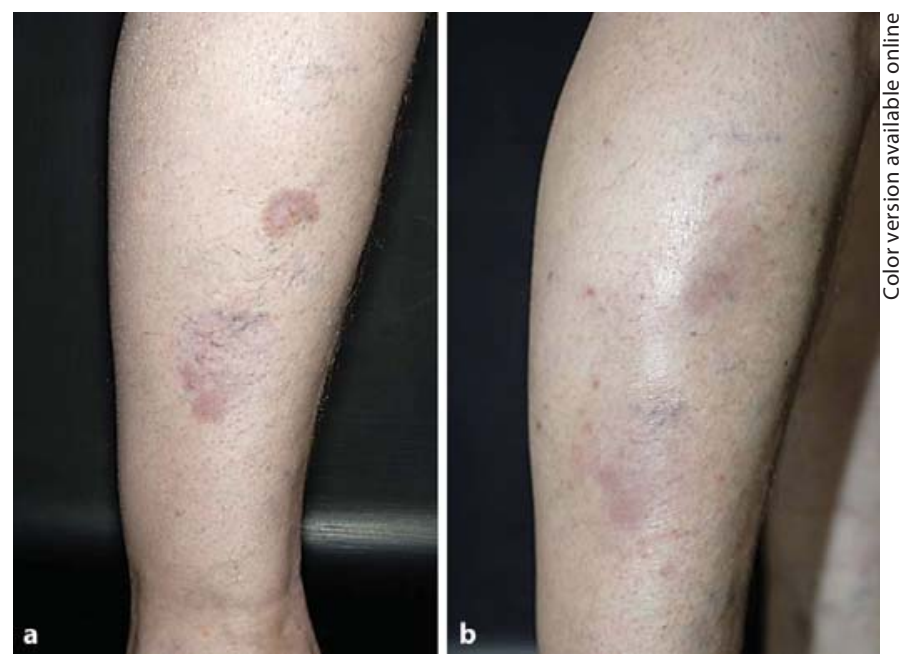

Fig. 1. NL on the right lower leg of a female patient (patient 4) before therapy (a) and 7 months after 6 cycles of PDT (b). A partial response was observed, and the patient was very satisfied with the outcome.

drugs, while other cases may respond to systemic therapy $[5,8]$.

The etiology remains subject to discussion. It has been proposed that diabetic microangiopathy is the main etiological agent, because similar changes can be seen in diabetic retinas and kidneys. Other theories about the development of NL suggest deposits of abnormal collagen or of immunoglobulins. Furthermore, metabolic changes and trauma have been discussed as etiological factors [3].

This exploratory study focused on a noninvasive approach for the therapy of NL with the use of a technique which offers the possibility of repeated applications. The overall response rate was $39 \%(7 / 18)$. Whereas partial cure was observed in 6 of 18 patients, dramatic improvement was noted in 1 patient only.

The mechanisms responsible for the response to therapy are not yet understood. PDT has been shown to elicit immunomodulatory effects that eventually may lead to tumor destruction. These effects include the modification of cytokine expression, induction of immune-specific responses, production of interleukin $1 \beta$, interleukin 2 , granulocyte colony-stimulating factor and tumor necrosis factor $\alpha[10,11]$. Kim et al. [12] have used PDT to successfully cure granuloma annulare, a granulomatous disease with certain similarities to NL. Since the actual photosensitizer - protoporphyrin IX - has been shown to accumulate in lymphatic infiltrates and inhibit T-cell proliferation [13], it can be hypothesized that this mech- 
anism was also effective in NL lesions treated with PDT.

With respect to the characteristics of the responders, there seemed to be no association with the duration of the disease. The group of responders included patients with ulcerations, hyperpigmented lesions, with and without diabetes comorbidity and with adverse events like erythema. Regarding comorbidity, clinical appearance and adverse events, no association with treatment outcome was observed. The only common variable we could identify was the use of MAL as the sensitizing agent.

One limitation of PDT for NL may be the dermal and subcutaneous localization of the disease, which is too deep to be reached by topical PDT which is most effective at a depth of 2-3 mm. Other reasons may be an inadequate penetration into altered tissue or the granulomatous character of the disease preventing cellular uptake of the photosensitizer.

Another limiting factor of PDT for NL could be pain. Even though it was not observed in a vast number of our patients, a few did report very strong discomfort during illumination. It has been shown previously that the inten- sity of pain significantly increased at the second PDT treatment [14]. We also observed an increase in pain with the number of PDT sessions. This may be due to an improved penetration of the topical agent because of excoriation of the epidermis after the first PDT treatments. Alternatively, the nociception in the dermis may have changed by the initial PDT itself. This may limit the acceptance by the patient and therefore the feasible number of PDT sessions needed for cure.

In conclusion, in this multicenter study PDT was shown to be effective in the treatment of NL in few cases only with a response rate of $39 \%$. We did not find specific clinical features of NL which would predict a response to PDT. A prospective and controlled study should now be started on the basis of the presented results to further evaluate the efficacy of PDT in NL.

\section{Acknowledgement}

We thank Dagmar Dick for superb technical assistance.

\section{References}

1 Lowitt MH, Dover JS: Necrobiosis lipoidica. J Am Acad Dermatol 1991;25:735-748.

2 Ferringer T, Miller F 3rd: Cutaneous manifestations of diabetes mellitus. Dermatol Clin 2002;20:483-492.

3 www.emedicine.com.

4 Petzelbauer P, Wolff K, Tappeiner G: Necrobiosis lipoidica: treatment with systemic corticosteroids. Br J Dermatol 1992;126:542545.

5 Darvay A, Acland KM, Russell-Jones R: Persistent ulcerated necrobiosis lipoidica responding to treatment with cyclosporin. $\mathrm{Br} \mathrm{J}$ Dermatol 1999; 141:725-727.

6 Littler CM, Tschen EH: Pentoxifylline for necrobiosis lipoidica diabeticorum. J Am Acad Dermatol 1987;17:314-316.
7 De Rie MA, Sommer A, Hoekzema R, Neumann HA: Treatment of necrobiosis lipoidica with topical psoralen plus ultraviolet $\mathrm{A}$. $\mathrm{Br}$ J Dermatol 2002;147:743-747.

8 Nguyen K, Washenik K, Shupack J: Necrobiosis lipoidica diabeticorum treated with chloroquine. J Am Acad Dermatol 2002;46: 34-36.

9 Kolde G, Muche JM, Schulze P, Fischer P, Lichey J: Infliximab: a promising new treatment option for ulcerated necrobiosis lipoidica. Dermatology 2003;206:180-181.

10 Heidenheim M, Jemec GB: Successful treatment of necrobiosis lipoidica diabeticorum with photodynamic therapy. Arch Dermatol 2006;142:1548-1550.
11 Korbelik M: PDT-associated host response and its role in the therapy outcome. Lasers Surg Med 2006;5:500-508.

12 Kim YJ, Kang HY, Lee ES, Kim YC: Successful treatment of granuloma annulare with topical 5-aminolaevulinic acid photodynamic therapy. J Dermatol 2006;33:642643.

13 Goffe BS: Disseminated granuloma annulare resolved with the T-cell modulator efalizumab. Arch Dermatol 2004; 140:12871288.

14 Lindeburg KE, Brogaard HM, Jemec GB: Pain and photodynamic therapy. Dermatology 2007;215:206-208. 